\title{
Evaluating The Effect of Intent Factors on the Student's Intention to Register for External Exams via The Internet: Directorate of Education in Dhi-Qar as A Case Study
}

\author{
Mohammed Jaber Farhan ${ }^{1}$, Bushra Sahi Chassab ${ }^{2}$ and Nassir Jabir Al-Khafaji ${ }^{3}$ \\ \{809895@gmail.com ${ }^{1}$, bushrasahi69@gmail.com ${ }^{2}$, nassir.farhan@stu.edu.iq $\left.{ }^{3}\right\}$
}

\author{
Directorate of Education, Thi-Qar, Iraq ${ }^{1}$ \\ Nassriyah Technical Institute, Southern Technical University, Iraq ${ }^{2,3}$
}

\begin{abstract}
This study seeks to identify the affected factors that impact the behavioural intention of students on online external exams registration in the directorate of education in Thi-Qar. The study also intended to identify whether students prefer online external exam registration in terms of attitude, subjective norms, and whether website design has an impact on them. Additionally, the current study looked at how students evaluate these criteria in terms of relevance when registering for external exams online. A basic random sampling procedure was used, and 347 people were given questionnaires. A total of 304 questionnaires were gathered, with 304 of them being deemed to be usable. Several statistical methods were used to examine the data, including descriptive analysis, regression test, reliability analysis, and correlation test. The findings demonstrated that students' attitudes, subjective norms, and website usability were all strongly associated. Furthermore, the outcomes of the study revealed that the most essential element was regarded to be website usability, with other characteristics having a moderate impact on student intention to register electronically. The findings of the present study may be useful in persuading officials at the Thi-Qar Directorate of Education to use online technology to speed up office operations.
\end{abstract}

Keywords: Website Usability, Subjective Norm, Attitude, Student Intention.

\section{Introduction}

The Internet has a significant impact on everyone's lifestyle, altering how people work, live, and learn. Hasan, et al. [1], Public lifestyles have altered dramatically as a result of the rapid rise of Internet technology. Salamat, et al. [2] Governments in developing nations attempt to give services to citizens using information technology and communications methods. As a result, ICT has introduced several changes to government services, such as online voting, driver's license renewal, voter registration, and so forth. COVID -19 affected the handling based on face-to-face on all the world. As well as, the spread of COVID-19 has left universities and educational institutions in a predicament[3]. Additionally, COVID-19 has affected Most businesses in the world, and employees and citizens are encouraged or forced to do business from home remotely. In addition, the demand for appropriate technology is growing. [4]. This leads us to the conclusion that students will have a greater opportunity to advocate for their 
continued enrolment in educational institutions, as well as for how successfully educational programs and services meet students' service expectations.[5].Developing countries such as Iraq have pushed to adopting online systems to overcome the implications of a pandemic in various fields. On this orientation, the directorate of education in Thiqar suggested adopting an online system to end suffering the students in registration of external exams. The online registration of external exams made students more independent of bureaucracy and reduce the lines of crowds. Every year more than 20 thousand come from Nasiriyah and districts to present on the external exam with a long line and spent a long time to complete their application without knowing if the result is accepting or not. Furthermore, the students who desires to register in the external exams come from different backgrounds and levels in technological skills. According to Hasbullah, et al. [6] Knowing about consumer behaviour and understanding what they require is critical for improving and attracting online customers. Depend on interview with manager of external exam department (Waleed, personal communication, January 4, 2021) stated that the online registration is a crucial and corner stone to rid of the crowds of student, enquiries about the conditions and have accurate database to search the documents. The objective of this study is to identify the effected factors that impact behavioural intention of student on online external exams registration to improve the services and less complaints issued from students in directorate of education in Thiqar.

\section{Literature Review}

\subsection{Theory of Reasoned Action (TRA)}

Fishbein and Ajzen [7] developed the TRA, which states that a person's intention to engage in a specific activity is the strongest predictor of whether they engage in that behaviour (2011). According to the TRA, consumer behaviour is influenced by their attitude and subjective norms toward the activity in question, as well as their behavioural intention. [8] and that based on these variables, it is possible to forecast customer behaviour. The study's guiding framework was the theory-reasoned-action (TRA) framework. The TRA was preferred to choose it from the TAM and TPB for a variety of reasons. Researchers are interested in researching theories that are less commonly used than the TAM, which was consistently applied in prior studies. Even though the Technology acceptance model has advantages For instance extensive use in the field of IT area, researchers are interested in researching theories that are less commonly used than the TAM[9]. Icke Ajzen and Martin Fishbein, the authors of the TRA theory, think that people make conscious judgments about how they act and that they are in control of most of their behaviour. According to this theory, humans make rational decisions about how to act. Even if a person is highly motivated by her views and subjective norms, if activities are not fully within volitional control, intervening contextual variables may prevent her from performing the behaviour.

\subsection{The Relationship between Attitude on trust and Intention to Online Registration}

Students can be persuaded or encouraged to use the online system to register if they have a trusting attitude. represents a consensus among experts on online trust that the nature and essential meaning of online trust are identical to that of face-to-face trust [10-13]. Online trust has been identified as an important factor since it reduces perceived risk and generates good 
recommendations, both of which influence a customer's decision [14-16]. According to [17] Trust inspired motivation to engage and contribute. Additionally, online trust increases the interactions of the individuals in the system [18]. Trust in the online system belongs to the government has a vitally important effect in adopting and using that service. As a result, propose the following hypothesis: Hypothesis 1: There is a positive relationship between attitude towards intention online external exams registration among students in the directorate of education in Thiqar

\subsection{The Relationship Between Subjective Norm And Intention to Online External Exams Registration.}

Ajzan \& Driver (1980) Subjective norms are defined as the perceived pressure exerted by others, such as neighbours, peers, friends, and those involved in the activity of interest, on the respondent's behaviour, either directly or indirectly. The subjective norm ( $\mathrm{SN}$ ) is a tool for measuring people's perceptions of whether or not other people with similar attitudes would or will not behave in the same way when it comes to technology.[19]. Aboelmaged and Gebba [20] According to the data, there was a favourable association between subjective norms and system adoption. In Kim, et al. [21] Subjective norms have a favourable association with the behaviour intention to utilize an online system, according to a study. This finding can be regarded as indicating that recommendations have a significant impact on a student's intention. As a result, propose the following hypothesis: Hypothesis 2: There is a significant relationship between subjective norm towards intention online external exams registration among students in the directorate of education in Thiqar.

\subsection{The Relationship Between Website Usability and Intention to Online External Exams Registration Among Students in The Directorate Of Education In Thi-Qar Province}

In their study, Barnes and Vidgen [22] Consumers perceive the website to be simple to operate and learn, navigate, and use, with clear and understandable interactions, which operationalized the concept of usability. As the usage of online systems grows more common in everyday life, system usability has become increasingly critical.[23]. Alam and Yasin [24] said that one component of usability that has been investigated and proven to be crucial is website design. Alam et al. [29] recognized that the design of the website is considering one of the distinctive features in the internet world. As well, Shergill and Chen [25] referred to those design elements of the website were selected as the most important factor influencing consumer views of online systems. The usability of the system reflects the degree of user satisfaction. Moreover, satisfaction plays a significant role in positive behavioural intention [26]. More useful websites tend to foster more positive attitudes toward online systems, whereas websites that are less accessible have the reverse impact [27]. According to Belanche, et al. [28] Usability has a favourable impact on consumers' willingness to use a website. As a result, it is proposed that a website's usability is positively associated with a student's intention to use the internet. As a result, propose the following hypothesis:

Hypothesis 3: There is a significant relationship between usability towards intention online external exams registration among students in the directorate of education in Thiqar. 


\section{Research Methodology}

Fishbein and Ajzen[7] developed a theoretical framework. There are three constructs, the first and second of which are based on Fishbein and Ajzen's Theory Reasoned Action (1980). Alam, et al. [29] added another variable to the research to make it more robust. It was proposed by Alam et.al [29] where it was determined that website usability is one of the factors that has been studied and found to be important. The TRA has been used to evaluate a range of behavioural intents in the past, Blood donation, bone marrow donation, and internet shopping are all options. [30]. The data reveal whether or whether this profile can alter the nature of those relationships, as well as the magnitude of the influence. Further investigation will identify the dominating personality trait that has the most impact on relationships. The researchers hope to acquire a better understanding of the goal of online registration and contribute new information to the corpus of knowledge on online systems by combining the frameworks.

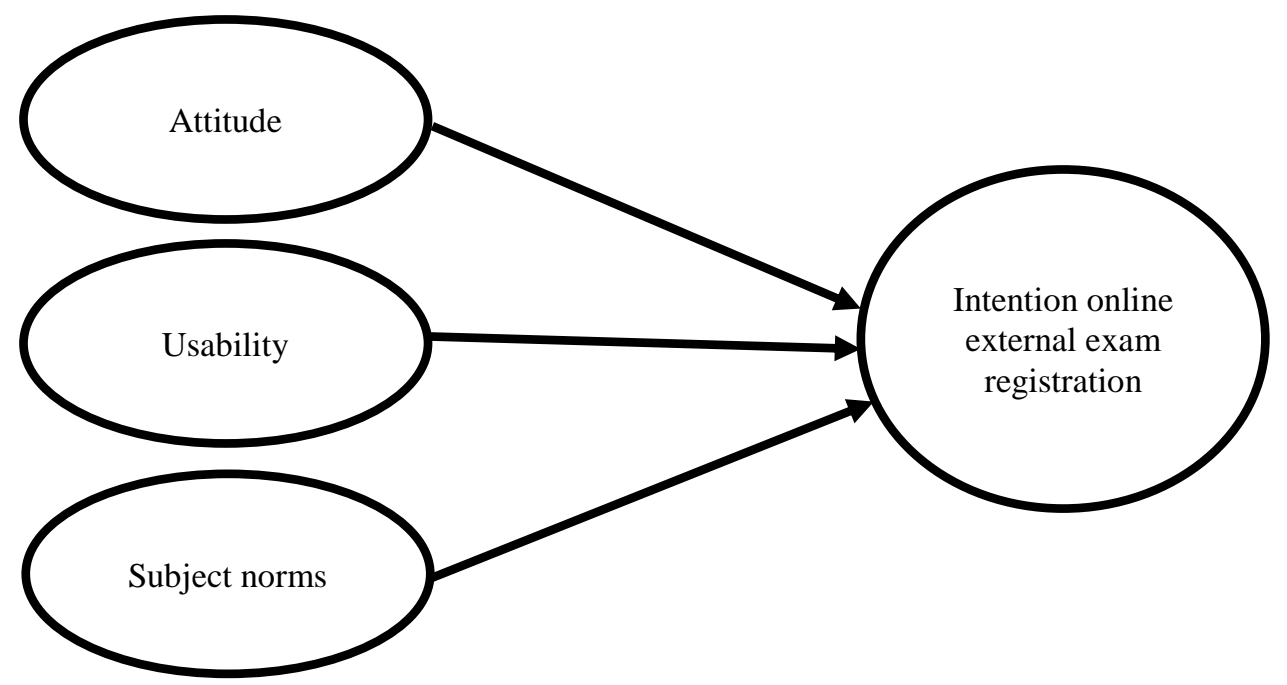

Fig 1. Framework for Research adopted from [6].

\section{Analysis \& Findings}

The sampling was taken from the students who use the online external exams registration in the directorate of education in Thiqar. The questionnaires were distributed on 347 students and only 305 questionnaire was return and valid. The Statistical Package for Social Science (SPSS 20) was used as an instrument to analyse the collected data that return from the students who participated in this study and their data were valid.

\subsection{Descriptive Statistics}

Table 1. Descriptive Statistics.

\begin{tabular}{|c|c|c|}
\hline Variables & Std. Deviation & Mean \\
\hline Attitude & 0.50168 & 4.3843 \\
\hline
\end{tabular}




\begin{tabular}{|c|l|l|} 
Subject norms & 0.47020 & 4.3704 \\
\hline usability & 0.36558 & 4.3889 \\
\hline Intention online registration & 0.65570 & 4.1574 \\
\hline
\end{tabular}

According to table 1, the mean values for all variables range from 4.3889 to 4.1574 . Website usability has the greatest mean (4.3889) and the smallest standard deviation (0.36558), Attitude and subjective standards come in second and third, with mean values of 4.3843 ( $\mathrm{SD}=0.50168)$ and 4.3704 ( $\mathrm{SD}=0.4702$, respectively. This indicates that responders have a high level of agreement on the subjective norm, attitude, and website usability. All of the variables had a standard deviation of less than one, the results were closely clustered around the mean, indicating that they were closely clustered around the mean.

\subsection{Reliability Analysis}

Table 2. Reliability Analysis.

\begin{tabular}{|l|c|c|}
\hline \multicolumn{1}{|c|}{ Variables } & $\begin{array}{c}\text { Cronbach } \\
\text { Alpha }\end{array}$ & $\begin{array}{c}\text { Number of } \\
\text { items }\end{array}$ \\
\hline Attitude & 0.737 & 4 \\
\hline Subject norms & 0.717 & 4 \\
\hline usability & 0.700 & 4 \\
\hline Intention online registration & 0.827 & 4 \\
\hline
\end{tabular}

The results of four sets of reliability testing are shown in table 2 . The test began with a question about trust. There are four aspects to attitude. On these four items, the reliability test was used, and Cronbach's alpha value was 0.737 . Subjective norm testing was the next step in the process. The subjective norm consisted of four items, with a reliability test result of 0.717 for subjective norm support. After that, the reliability test moved on to the third variable, which was website usability. There are four things in the website usability category that have a dependability value of 0.7 . The final run was to determine whether you intended to quit. In this study, the intention to register online was measured using a four-item questionnaire. The intention to register online has a dependability score of 0.827 .

\subsection{Correlation Analysis}

Table 3: Person correlation for variables.

\begin{tabular}{|l|l|l|r|l|l|l|}
\hline \multicolumn{2}{|l|}{} & Attitude & $\begin{array}{l}\text { Subject } \\
\text { norms }\end{array}$ & usability & $\begin{array}{c}\text { Intention } \\
\text { online } \\
\text { registration }\end{array}$ \\
\hline \multirow{2}{*}{} & Attitude & $\begin{array}{l}\text { Person } \\
\text { Coefficient }\end{array}$ & 1.000 & & & \\
\cline { 3 - 6 } & $\begin{array}{l}\text { Significance } \\
\text { (2-tailed) }\end{array}$ &. & & & \\
\cline { 2 - 7 } & Subject norms & $\begin{array}{l}\text { Person } \\
\text { Coefficient }\end{array}$ & $.508^{* *}$ & 1.000 & & \\
\hline
\end{tabular}




\begin{tabular}{|c|c|c|c|c|c|}
\hline & $\begin{array}{l}\text { Significance } \\
\text { (2-tailed) }\end{array}$ & 0.000 & & & \\
\hline \multirow[t]{2}{*}{ usability } & $\begin{array}{l}\text { Person } \\
\text { Coefficient }\end{array}$ & $.427^{* *}$ & $.417^{* *}$ & 1.000 & \\
\hline & $\begin{array}{l}\text { Significance } \\
\text { (2-tailed) }\end{array}$ & .000 & .000 & & \\
\hline \multirow{2}{*}{$\begin{array}{l}\text { Intention } \\
\text { online } \\
\text { registration }\end{array}$} & $\begin{array}{l}\text { Person } \\
\text { Coefficient }\end{array}$ & $.512^{* *}$ & $.541^{* *}$ & $.552^{* *}$ & 1.000 \\
\hline & $\begin{array}{l}\text { Significance } \\
\text { (2-tailed) }\end{array}$ & 0.000 & 0.000 & 0.000 & . \\
\hline
\end{tabular}

According to the findings, the correlation coefficient between subjective norms and attitude is 0.508 , or 50.8 percent at the $99 \%$ confidence interval; website usability and attitude are 0.427 , or 42.7 percent at the $99 \%$ confidence interval, and intention to register online and attitude is 0.512 , or 51.2 percent at the $99 \%$ confidence interval. This means that the Pearson's correlation between all of the variables and attitude was less than 0.70, implying that each of the variables and attitude is the independent variable. In terms of relationship strength, the findings point to a moderate relationship. Since all variables are significant at 0.00 , attitude is significant to all of them. According to the findings, the correlation coefficient between website usability and the subjective norm is 0.417 , or 41.7 percent at the $99 \%$ confidence interval, and intention to register online and the subjective norm is 0.541 , or 54.1 percent at the $99 \%$ confidence interval. In terms of relationship strength, subjective norm and attitude indicate a moderate association, whereas intention to register online and website usability indicates a moderate relationship. Because all variables are significant at 0.00 , the subjective norm is significant for all of them. The value of the correlation coefficient between website usability and intention to register online is 0.552 or 55.2 percent at the 99 percent confidence range, according to the findings. This means that the Pearson's correlation between website usability and all of the variables was less than 0.70 , implying that attitude and each of the variables are separate variables. In terms of relationship strength, the results of website usability and attitude indicate a moderate association, whereas subjective norm and online intention register indicate a significant relationship. Since all variables are significant at 0.000 , All variables are affected by website usability.

\subsection{Regression Analysis}

Table 4. Regression analysis.

\begin{tabular}{|c|c|c|}
\hline Independent Variables & Significance value & Beta \\
\hline Attitude & 0.009 & 0.177 \\
\hline Subject norms & 0.000 & 0.337 \\
\hline usability & 0.004 & 0.348 \\
\hline $\mathrm{R}^{2}$ & SIG. & F VALUE \\
\hline 0.419 & 0.000 & 12.014 \\
\hline
\end{tabular}

Table 4 shows that the association between attitude and intention to register online is significant at the 99 percent confidence level, with a positive beta value of 0.177 . This suggests that a good 
attitude toward taking an external exam has a considerable impact on the desire to register online. Hypothesis 1 is so accepted. The results also reveal that subjective norms have a substantial positive connection (beta value $=0.337$ ) to register online at a confidence level of 99 percent (sig=.1). As a result, hypothesis 2 is supported, which states, "There is a substantial association between subjective norm and intention to register for online external exams among students in the directorate of education in Thiqar.". This suggests that a student's social influence is greater. In other words, students are more likely to accept a trusted individual's behaviour, which boosts their desire to perform it. Typically, students seek information from their most trusted sources, such as peers and friends. A student's close friends and family members may be able to persuade him or her to take the recommended action. The association between the intention to register online and website usability was determined to be significant (sig=.000) at the $99 \%$ significant level, with a positive beta of 0.348 . This shows that the desire to register online is strongly linked to the usability of a website. As a result, the third hypothesis is now considered valid. This hypothesis is significant because students are more likely to register online when the website provides information that is simple to understand. The more appealing a website is, the more likely people are to register online. The R2 for this study is 0.419 , implying that website usability, subjective norm, and attitude, and can explain 41.9 percent of the variation in online registration intention. This suggests that the study's findings were almost average in explaining registration intent to register online, with other factors accounting for the remaining 58.1 percent.

\begin{tabular}{|l|l|}
\hline \multicolumn{1}{|c|}{ Hypothesis } & Remarks \\
\hline $\begin{array}{l}\text { There is a positive relationship between attitude towards intention online } \\
\text { external exams registration }\end{array}$ & Accepted \\
\hline $\begin{array}{l}\text { There is a positive relationship between subjective norm towards intention } \\
\text { online external exams registration }\end{array}$ & Accepted \\
\hline $\begin{array}{l}\text { There is a positive relationship between usability towards intention online } \\
\text { external exams registration }\end{array}$ & Accepted \\
\hline
\end{tabular}

The hypothesis testing results from the Regression Analysis are summarized in Table 5. The first hypothesis, that there is a positive association between intention to register for external tests online and attitude, is validated, as is the second hypothesis, that there is a positive association between intention to register for external exams online and subjective norm. However, the third hypothesis, 'There is a positive relationship between usability and intention to register for external exams online,' is also well supported. It demonstrates that in this investigation, all three hypotheses are accepted.

\section{$5 \quad$ Discussion and Conclusion}

According to the findings, one's attitude toward online registration has a substantial positive correlation with one's desire to register online. This attribute in this study relates to the online registration for external exams. They have a positive attitude toward their conduct as it pertains to online registration to encourage students to register. In other words, students will be more likely to register if the online external exam registration has a constructive approach toward their demands. The results were in line with TRA (Fishbein and Ajzen, 1980), which revealed a positive link between behaviour and attitude. Because students are invisible and have no face-to-face contact, online registration and student trust are critical. Students would be attracted to online registration if the greatest services were provided to them. Hypothesis 2 was 
likewise accepted, in which subjective norm was found to have a positive and significant relationship with the desire to register online. The value of the Person correlation is 0.541 , showing that the factor influences the intention to register online by approximately $50 \%$. According to Ajzen and Fishbein (1975), A person's subjective norm is linked to their normative belief, which is described as a fear of a relevant referent individual or group accepting or disapproving of the person's behaviour. To put it another way, advances in normative thinking will improve subjective norms, which will indirectly boost a person's registration intention. This conclusion, like attitude, was corroborated by Theory Reasoned Action (Fishbein and Ajzen, 1975), which revealed a relationship between subjective norms and conduct. This study focused on friends and peers because they use and spend far more time online than family and relatives. The findings were also in line with what had been seen in prior studies. Karaiskos (2011) stated that among the social variables, the subjective norm has been deemed a crucial determinant of intention. It reveals that encouraging group remarks have a significant impact on those closest to students' acceptance. Students will seek counsel from a trusted referent individual or group, such as friends and peers, because the information from others may be distorted. The third hypothesis looked at the link between website usability and online registration intent, and it was shown to be true. This suggests that as the website becomes more user-friendly, the likelihood of students registering for external exams online will rise. In online registration, website usability refers to the student's expectation that the website would be simple to use and understand. Page loading, navigation, content, security, efficiency, and consumer focus are five important factors that should be addressed while developing a website, according to Osama et al. (2010). Aidil, (2010) reinforced this research by identifying website design characteristics as a dominating or powerful component that influences people's attitudes toward online systems because websites play a key role in attracting people to the system. The first impression and entry point for student online registration for external exams is the website.

\section{References}

[1] H. F. A. Hasan, A. Ilias, R. A. Rahman, and M. Z. A. Razak, "Service quality and student satisfaction: A case study at private higher education institutions," International Business Research, vol. 1, no. 3, pp. 163-175, 2008.

[2] M. A. Salamat, S. Hassan, and M. S. Muhammad, "Electronic participation in Malaysia," Journal of e-Government Studies and Best Practices, vol. 2011, no. 270543, pp. 1-11, 2011.

[3] M. Calbi et al., "The consequences of COVID-19 on social interactions: an online study on face covering," Scientific reports, vol. 11, no. 1, pp. 1-10, 2021.

[4] F. M. E. Sepasgozar, U. Ramzani, S. Ebrahimzadeh, S. Sargolzae, and S. Sepasgozar, "Technology acceptance in e-governance: A case of a finance organization," Journal of Risk and Financial Management, vol. 13, no. 7, p. 138, 2020.

[5] Y. Chen and F. Q. Fu, "The behavioral consequences of service quality: An empirical study in the Chinese retail pharmacy industry," Health marketing quarterly, vol. 32, no. 1, pp. 14-30, 2015.

[6] N. A. Hasbullah, A. Osman, S. Abdullah, S. N. Salahuddin, N. F. Ramlee, and H. M. Soha, "The relationship of attitude, subjective norm and website usability on consumer intention to purchase online: An evidence of Malaysian youth," Procedia Economics and Finance, vol. 35, pp. 493$502,2016$.

[7] M. Fishbein and I. Ajzen, Predicting and changing behavior: The reasoned action approach. Taylor \& Francis, 2011.

[8] T. Hansen, M. S. Risborg, and C. D. Steen, "Understanding consumer purchase of free-of cosmetics: A value-driven TRA approach," Journal of consumer behaviour, vol. 11, no. 6, pp. 477-486, 2012. 
[9] H. Amin, "An analysis of online banking usage intentions: an extension of the technology acceptance model," International Journal of Business and Society, vol. 10, no. 1, p. 27, 2009.

[10] C. L. Corritore, B. Kracher, and S. Wiedenbeck, "On-line trust: concepts, evolving themes, a model," International journal of human-computer studies, vol. 58, no. 6, pp. 737-758, 2003.

[11] Y. H. Fang, C. M. Chiu, and E. T. Wang, "Understanding customers' satisfaction and repurchase intentions: An integration of IS success model, trust, and justice," Internet research, 2011.

[12] S. L. Jarvenpaa and V. S. Rao, "Trust in online consumer exchanges: Emerging conceptual and theoretical trends," in E-Commerce and the Digital Economy: Routledge, 2015, pp. 255-272.

[13] V. Shankar, G. L. Urban, and F. Sultan, "Online trust: a stakeholder perspective, concepts, implications, and future directions," The Journal of strategic information systems, vol. 11, no. 3-4, pp. 325-344, 2002.

[14] Y. H. Chen and S. Barnes, "Initial trust and online buyer behaviour," Industrial management \& data systems, 2007.

[15] M. Fan, Y. Tan, and A. B. Whinston, "Evaluation and design of online cooperative feedback mechanisms for reputation management," IEEE Transactions on Knowledge and Data Engineering, vol. 17, no. 2, pp. 244-254, 2005.

[16] K. Hassanein and M. Head, "Manipulating perceived social presence through the web interface and its impact on attitude towards online shopping," International Journal of Human-Computer Studies, vol. 65, no. 8, pp. 689-708, 2007.

[17] W. C. Kim and R. Mauborgne, "Fair process: Managing in the knowledge economy," Harvard business review, vol. 81, no. 1, pp. 127-136, 2003.

[18] M. Turilli, A. Vaccaro, and M. Taddeo, "The case of online trust," Knowledge, Technology \& Policy, vol. 23, no. 3-4, pp. 333-345, 2010.

[19] R. S. Al-Maroof, S. A. Salloum, A. E. Hassanien, and K. Shaalan, "Fear from COVID-19 and technology adoption: the impact of Google Meet during Coronavirus pandemic," Interactive Learning Environments, pp. 1-16, 2020.

[20] M. Aboelmaged and T. R. Gebba, "Mobile banking adoption: an examination of technology acceptance model and theory of planned behavior," International Journal of Business Research and Development, vol. 2, no. 1, 2013.

[21] E.-J. Kim, J. J. Kim, and S.-H. Han, "Understanding Student Acceptance of Online Learning Systems in Higher Education: Application of Social Psychology Theories with Consideration of User Innovativeness," Sustainability, vol. 13, no. 2, p. 896, 2021.

[22] S. J. Barnes and R. T. Vidgen, "An integrative approach to the assessment of e-commerce quality," J. Electron. Commerce Res., vol. 3, no. 3, pp. 114-127, 2002.

[23] L.-M. N. Tchouakeu, M. K. Hills, M. H. Jarrahi, and H. Du, "On-line course registration systems usability: a case study of the e-Lion course registration system at the Pennsylvania State University," International Journal of Information Systems and Social Change (IJISSC), vol. 3, no. 4, pp. 38-52, 2012.

[24] S. S. Alam and N. M. Yasin, "An investigation into the antecedents of customer satisfaction of online shopping," Journal of Marketing Development and Competitiveness, vol. 5, no. 1, pp. 71$78,2010$.

[25] G. S. Shergill and Z. Chen, "WEB-BASED SHOPPING: CONSUMERS'ATTITUDES TOWARDS ONLINE SHOPPING IN NEW ZEALAND," Journal of electronic commerce research, vol. 6, no. 2, p. 78, 2005.

[26] R. L. Oliver, Satisfaction: A behavioral perspective on the consumer: A behavioral perspective on the consumer. Routledge, 2014.

[27] S. A. Becker and F. E. Mottay, "A global perspective on web site usability," IEEE software, vol. 18, no. 1, pp. 54-61, 2001.

[28] D. Belanche, L. V. Casaló, and M. Guinalíu, "Website usability, consumer satisfaction and the intention to use a website: The moderating effect of perceived risk," Journal of retailing and consumer services, vol. 19, no. 1, pp. 124-132, 2012.

[29] S. S. Alam, Z. Bakar, H. B. Ismail, and M. Ahsan, "Young consumers online shopping: an empirical study," Journal of Internet Business, no. 5, 2008. 
[30] S. Chuchinprakarn, "Application of the theory of reasoned action to on-line shopping," Knowledge Center E-paper Bangkok University, pp. 1-7, 2005. 